\title{
Test@work: evaluation of workplace HIV testing for construction workers using the RE-AIM framework
}

Wendy Jones ${ }^{1}$, Sarah Somerset ${ }^{1}$, Catrin Evans ${ }^{1}$, Katharine Whittingham ${ }^{1}$, Matthew Middleton ${ }^{2}$ and Holly Blake ${ }^{1,3^{*}}$

\begin{abstract}
Background: Community testing for HIV can reach previously untested populations but is rarely offered in workplaces. Targeting the construction sector could reach workers from high risk populations.

Methods: The RE-AIM framework was used to evaluate Test@Work, a workplace HIV testing intervention for construction workers implemented at 21 events (10 companies) in the UK.

Test@Work had three components: 1) an online health toolkit to inform managers about health screening and HIV testing; 2) general health checks; and 3) opt-in HIV consultation and testing. Quantitative data were collected using registration and exit questionnaires with workers $(n=426)$ and pre/post-event questionnaires with managers $(n=$ 15), with qualitative analysis of free text responses.

Results: Reach 426 individuals had health checks. Participants were broadly representative of the UK construction workforce, but with a higher proportion of permanent workers. Most workers reported being in good health but also believed their work had an adverse impact on their health. Effectiveness: $97 \%$ of health check participants opted to have a consultation about sexual health $(n=413)$ and $82 \%$ had an HIV test $(n=348)$, of whom $78 \%$ had not previously been tested. All HIV tests were non-reactive. HIV testing at work was considered acceptable by most participants. Participants reported learning new things about their health (74\%), said they would make changes as a result (70\%) and felt confident of success (median score 8/10). Adoption: Recruitment of companies was challenging and time consuming. Seven of the participating companies were very large, employing over 1000 workers, which is atypical of construction generally. Implementation: All events were completed as planned and were considered successful by all parties. Maintenance: All managers would arrange further events if they were offered them. Six managers incorporated sexual health awareness into their health programmes, but this was not possible for many as health agendas were set centrally by their organisations.
\end{abstract}

Conclusions: Opt-in HIV testing, when embedded within a general health check, has high uptake and acceptability in the UK construction sector, and reaches individuals at risk for HIV who may not otherwise attend for testing. Cost-effectiveness of this approach is yet to be determined.

Trial registration: ClinicalTrials.gov Identifier: NCT04292002.

Keywords: HIV testing, Workplace, Health promotion, Construction, Health checks, Occupational health, RE-AIM

\footnotetext{
*Correspondence: holly.blake@nottingham.ac.uk

${ }^{1}$ School of Health Sciences, University of Nottingham, Nottingham, UK

${ }^{3} \mathrm{NIHR}$ Nottingham Biomedical Research Centre, Nottingham, UK

Full list of author information is available at the end of the article
}

(c) The Author(s). 2021 Open Access This article is licensed under a Creative Commons Attribution 4.0 International License, which permits use, sharing, adaptation, distribution and reproduction in any medium or format, as long as you give appropriate credit to the original author(s) and the source, provide a link to the Creative Commons licence, and indicate if changes were made. The images or other third party material in this article are included in the article's Creative Commons licence, unless indicated otherwise in a credit line to the material. If material is not included in the article's Creative Commons licence and your intended use is not permitted by statutory regulation or exceeds the permitted use, you will need to obtain permission directly from the copyright holder. To view a copy of this licence, visit http://creativecommons.org/licenses/by/4.0/ The Creative Commons Public Domain Dedication waiver (http://creativecommons.org/publicdomain/zero/1.0/) applies to the data made available in this article, unless otherwise stated in a credit line to the data. 


\section{Background}

The last twenty years have seen substantial developments in the treatment and prevention of HIV. Worldwide, 26 million people are receiving lifelong ART (antiretroviral therapy) and the rate of new infections is falling in many countries. Within the United Kingdom (UK), $97 \%$ of those who have been diagnosed with the illness are receiving treatment. Viral suppression has been achieved in $97 \%$ of those being treated so that they are no longer considered infectious and their life expectancy and quality of life are close to normal [1]. There have also been substantial improvements in diagnosis rates, particularly for men who have sex with men (MSM). However, an estimated 19\% of those living with the disease worldwide do not know their HIV status. Within the UK, there remain an estimated 7500 undiagnosed cases and $43 \%$ of cases are diagnosed late, resulting in higher mortality and an ongoing risk of transmission to others. Late diagnosis is more common amongst men who are heterosexual and older [2, 3]. Additionally, both HIV prevalence and late diagnosis in the UK are higher amongst those with black ethnicity and those born in countries with a high prevalence [4]. More than $50 \%$ of infections are acquired post-migration for these populations $[5,6]$ highlighting the need for ongoing education and effective testing programmes.

Increasing testing uptake, particularly for those at greatest risk, has been identified as the single most important action to improve the management of HIV in the UK [7]. Advances in recent years to support this have included self-sampling and self-testing kits, shown to have high sensitivity and specificity, high effectiveness (particularly amongst black and Asian men in the UK) and good acceptability $[3,7,8]$. There have also been developments in the variety of settings which are used for testing. For example, primary health care settings such as general practices (GP) in high prevalence areas are encouraged to test routinely; sexual health clinics are advised to test those who attend for other services, as often as every three months for those at greatest risk [1]. Community-based testing has been introduced in many countries, often targeting high risk populations e.g., through stalls at Gay Pride events, bars and saunas, also in outreach clinics away from main health care centres [9-13]. These events are typically more expensive and report lower rates of positive results than more traditional testing routes but have successfully identified cases which may have been missed through normal channels.

Community testing has also been conducted in workplace settings, but these interventions have mostly been in sub-Saharan Africa [11]. Programmes to test, educate and address HIV-related stigma are reported, for example in South Africa [14], Uganda [15] Zambia [16] and Zimbabwe [17]. These studies have focused particularly in sectors with male dominated populations and a high proportion of migrant workers, such as construction and security. Such programmes are challenging; considerable efforts are needed to address difficulties such as the stigma associated with a positive diagnosis, fear of compromised confidentiality and low perceived HIV risk [18, 19]. Yet, workplace interventions have shown to be an important route for testing in populations with high HIV prevalence [17, 20], risky lifestyle behaviours and low access to health care [19, 21, 22]. Worksite HIV testing programmes have demonstrated the particular importance of accessibility and convenience for HIV testing with these hard-to-reach populations [17].

The potential for workplace HIV testing programmes outside of Africa has largely been overlooked. Systematic reviews by Thornton et al. [12] and Croxford et al. [13] investigated HIV testing in non-healthcare settings in 'resource-rich' countries and the European Union (EU)/ European Economic Area (EEA) respectively, but did not identify any workplace testing. However, recent studies have identified that HIV testing in UK workplaces, when combined with general health checks, has high uptake and good acceptability [23-25].

Some of the risk factors associated with high prevalence of HIV in African workplaces [21, 26] are paralleled in the UK construction sector. This presents opportunities to detect undiagnosed cases amongst people who might not access testing through other routes. For example, in the UK (like elsewhere) construction work employs many workers from migrant populations [27], as well as transient or travelling workers, living too far from their homes to be able to commute on a daily basis [28-30]. Living away from home increases the likelihood of risky sexual behaviours $[21,22,31]$. Other factors associated with HIV transmission are drug use and high alcohol intake [21], both common in the construction workforce in many countries, including the UK [30, 32-36].

Problematic alcohol and drug use in construction are part of a wider picture of increased health risk in this population. Smoking [37, 38], obesity [38-40], and poor mental health [41-43] are prevalent in the sector. For example, during the construction of the Olympic Park for London 2012, $41 \%$ of the workforce were found to be overweight, $28 \%$ were obese and $30 \%$ had high blood pressure [44]. These health risks, influenced by socioeconomic factors [40, 45-47], add to harm from specific workplace hazards such as noise, vibration, silica dust and hazardous chemicals [48]. As a result, construction workers are at increased risk of early disability or death compared with other populations, with high prevalence of cardiovascular disease, respiratory ill-health and 
musculoskeletal conditions [49-55]. Beyond individual health impacts, there are financial consequences for workers, since pension changes require them to continue in employment until aged 67 years and beyond $[56,57]$. There are substantial costs for construction employers [58] and the premature loss of workers contributes to the growing skill shortages in the UK construction sector [59]. Supportive interventions to help address these factors are therefore important for individual workers and the wider construction community.

The inclusion of wider health checks when offering workplace HIV testing has been recommended as a strategy to increase uptake and reduce the risk of HIVrelated stigma $[15,60]$. Workplace health checks in construction, therefore, offer on opportunity to address both the potential for undiagnosed HIV and the wider health challenges for this population. Recent studies by Blake et al. $[23,24]$ suggest that this is a promising approach in the UK, with high workforce acceptability, but no interventions of this nature have targeted the construction workforce specifically.

\section{RE-AIM}

RE-AIM is a framework for planning and evaluating health promotion interventions [61, 62], to ensure they will work in 'real world' scenarios. It evaluates not just the effectiveness of an intervention (which can be disproportionately high in a targeted, carefully chosen population) but also the representativeness of the study population and setting. This increases confidence that an intervention will still be effective when disseminated outside the original setting.

The RE-AIM framework [62] consists of five dimensions. Reach is a measure of participation, also an assessment of participant characteristics, and whether they are representative of the targeted population. Effectiveness assesses the impact of the intervention on individual outcomes, considering both positive and negative consequences. It also considers whether effectiveness varies between sub-groups. Adoption examines whether organisations which participate have similar characteristics to those which do not, and what the barriers might be to adoption. Implementation can be described in terms of how consistently the programme is delivered; it should also examine how much it costs. Finally, Maintenance assesses the long-term effect of a programme after it has been completed.

RE-AIM has evolved over time, with additional criteria identified or added by different authors [63, 64]. Mixed methods are increasingly advocated $[63,65]$ in place of the purely quantitative approach described in the original model [61]. It has also been acknowledged that pragmatic and less prescriptive approaches to using the model for planning and evaluation can increase its value and uptake in many public health settings, and that priority should be given to those aspects of the tool which are most appropriate for the research question, setting and stakeholders [62].

\section{Project aims}

We aimed to evaluate the delivery of Test@Work, a workplace HIV testing programme in the UK. In Test@Work, HIV testing was incorporated within a wider health check to increase its acceptability and usefulness to participating companies and workers. The research was conducted in the construction sector as its workforce are at high risk of poor health in addition to being at potentially increased risk of HIV. The aims of this study were to use RE-AIM to assess the suitability of the UK construction sector as a location for workplace HIV testing and wider health testing, and to identify learning points for community HIV testing initiatives in the future.

\section{Methods \\ Research design}

Test@Work, a free workplace health check programme, was offered to construction companies. The acceptability and perceived usefulness of the programme were assessed using quantitative and qualitative data from questionnaires completed by participating workers and representatives of the construction companies. Test@Work was prospectively registered (ClinicalTrials.gov Identifier: NCT04292002).

\section{Setting and participants}

Participating companies were construction or construction-related organisations, which had one or more sites operating within a designated geographical area in the Midlands, UK. Potential participant companies were identified from public records and contact made by email with a follow-up phone call. For companies which agreed to take part, pre-arranged health check events were scheduled to take place at their premises/ worksite. Further details of the recruitment process are discussed in 'Adoption' (below).

Within these companies, all workers present on the day(s) of testing were entitled to participate. A worker could be a direct employee, agency worker or a selfemployed worker. They might work for the company which had arranged the event; or any of their subcontractors on site (e.g. specific trades or disciplines). Workers were invited to participate by a range of methods including email or personal invitation from their manager or supervisor; poster; or personal invitation by the research team on the day of the event. Workers were generally permitted to attend during their working time, they were not required to use break or 
lunch times for health checks, although some preferred to. Wherever possible, appointments were booked in advance, but there was also scope for individuals to turn up for an ad-hoc health check at most events.

\section{Test@work: workplace health check programme}

The programme had three components.

\section{Online health toolkit}

An online health toolkit, "Test@Work: Creating Healthy workplaces: a toolkit for employers" was developed. The development and evaluation of this toolkit has been described elsewhere [66]. The toolkit was circulated to all participating companies to increase managers' understanding of the purpose and value of HIV testing and other health checks. The toolkit was self-directed and took around $60 \mathrm{~min}$ to complete.

\section{General health checks}

All participants were offered a range of general health checks: height, weight, BMI (body mass index), waist/hip measurements, blood pressure, Patient Health Questionnaire-2 item (PHQ-2, mental health check) [67]. Participants could choose which tests they wished to have. Health checks and tailored feedback were based on the Making Every Contact Count approach to delivering brief health promotion intervention and used tools from Health Education England [68]. Health check results were noted on a record sheet which each participant took away with them. Where appropriate (e.g. where test results fell outside recommended ranges), they were advised to take this to their GP or pharmacist and seek further advice. They were also given verbal guidance and a written information pack. No health data were kept by the research team. Further detail about the health checks and delivery process are described elsewhere [69].

Health checks were conducted by a team of volunteer healthcare trainees from professional backgrounds including nursing, physiotherapy, medicine and health psychology. Volunteers were trained to perform the tests and supported throughout as part of a programme to enhance interprofessional learning in healthcare education [69].

\section{HIV testing and consultation}

All participants were offered a consultation, followed by an optional HIV test. If concerns were raised or risks identified in relation to other sexual health topics such as chlamydia, gonorrhoea etc. these were addressed briefly, with onward referral to a sexual health clinic where appropriate. Testing was provided by independent HIV specialists from one of two outreach or charitable organisations that had substantial experience of providing HIV testing in the community and had clinical governance arrangements in place with NHS England Clinical Commissioning Groups (CCGs). Test kits were 4th generation Alere Determine ${ }^{\text {Tx }} H I V-1 / 2$. These provide a test result within twenty minutes enabling participants to be given their test results before they left the health check event. Testing was conducted in accordance with the WHO "5 Cs": Consent, Confidentiality, Counselling, Correct results and Connections [70].

1. Consent: Attending an HIV consultation was an optional element of the health check (attendance at the health check was also voluntary). All individuals who had a consultation were then given further detailed information before they gave informed consent if they wished to proceed to testing.

2. Confidentiality: Testing was conducted by the HIV specialist(s) in a room or location separate from other health checks. Results were given to individuals face to face after test results had developed. No information about individuals or their test results was shared with the health check team or the employer by the HIV specialist. The only information provided to the research team was whether each individual (identified by participant number) had undertaken a test and/or a health consultation; and the total number of reactive/nonreactive test results for the whole series of events.

3. Counselling: All participants were given information about what was being offered and why; the risk factors associated with HIV (sexual practices and number of partners, sex work, drug use, blood transfusion) and participants' own personal level of risk; and information about the test offered and how results would be given and followed up.

4. Correct results: The test strips used have high clinical sensitivity and specificity and include builtin controls to confirm accurate testing. Test strips were checked to make sure they were in-date. Results were given to each individual before they left the event, with name and date of birth being checked to match results and individual.

5. Connections: a procedure was in place to respond to any reactive tests. UK guidance is for this to follow locally determined pathways. For both partner organisations a reactive test would be followed up with an urgent blood test at a specialist centre, with laboratory analysis. Confirmed positive tests would lead to referral to a treatment location, which could be close to the worker's home or workplace, according to individual preference. All treatment for HIV is provided free of charge in the UK regardless of an individual's personal circumstances e.g. immigration or employment 
status [1]. Access to a helpline for interim support was also available.

\section{Research data collection}

All participating workers were asked to complete two anonymous, brief questionnaires (Additional file 1). Before the event, they were asked for demographic information and to confirm whether they had previously had an HIV test. After the event they were asked about their experience of the event e.g., whether they had learned anything, whether they intended making changes to their health as a result. Most questions were closed, with multiple choice answers, and one question was open ('is there anything else you would like to tell us?').

The main contact for each company was asked to complete two questionnaires (Additional file 2). This population are referred to as 'managers': they were a mix of site managers, health and safety $(H \& S)$ managers and professionals with responsibility for wellbeing. The first questionnaire included details about the company such as the number of workers and the demographics of the working population. The second, completed after the event, asked a series of open questions about their experiences of the event.

Records kept by delivery partners (healthcare volunteers and HIV specialists) indicated which tests were completed for each anonymised individual (Additional file 3). An interview was conducted with the lead researcher who had organised the events, to gather information on the process of recruiting companies to participate and the organisation and implementation of the events.

Informed consent to participate in the research was obtained from all participants. All methods were carried out in accordance with the relevant guidelines.

\section{Data analysis}

Quantitative data were analysed using IBM SPSS statistics V27 (IBM Corp., Armonk, N.Y., USA). All data were categorical or ordinal (age was condensed into four categories). Comparison between groups or between participant data and comparator populations were made using chi-square tests for categorical data (or Fisher's exact test where indicated) or Mann-Whitney $U$ test for continuous/ordinal data e.g. a response on a scale of 110 [71].

Qualitative data from free text responses to open questions in the post-event worker and manager questionnaires were uploaded to NVivo 12 Pro, organised by the questions which were being answered. They were coded using an inductive process initially, with codes being created to reflect the thoughts being expressed in the data [72, 73]. Codes were then mapped against the five dimensions of the RE-AIM framework. Comments were coded to more than one node or theme where appropriate [74].

Qualitative and quantitative findings have been combined in this report, using the qualitative outputs to support and add richness to the numerical data set.

\section{RE-AIM dimensions in this research}

Table 1 shows details of indicators and data sources for the RE-AIM dimensions. To examine Reach in this paper, the study population is described in terms of their demographic characteristics. They are compared to the target population, i.e. the UK construction workforce. The study population is also described in terms of their health at work, as this reflects the value of targeting this population, and whether they might benefit from health checks and guidance. The primary outcome for Effectiveness is the uptake of HIV testing by participants attending general workplace health checks and whether this varies between subgroups. Additional outcomes relate to the uptake of health checks generally, and the perceived impact of these. Indicators of the acceptability and perceived usefulness of HIV testing are also included. To explore Adoption, summary data from the participating companies are presented and compared to sector data. Additional information is included about those companies which were approached but did not participate; perceived reasons for non-participation; and the experience of recruiting companies to the study. The focus of Implementation is how successful the events were, based on feedback from the managers and workers who were involved in events. Cost information is also presented. Maintenance is operationalised as the sustainability of the programme: have organisations made long term changes as a result of this event, and how likely is it that they would participate in future events?

\section{Results}

A total of 426 individuals participated in health checks at 21 events, the number of participants per event ranged from 8 to 34 . A further 10 individuals agreed to participate but left the event prematurely as the result of a fire drill and were therefore lost to follow up. Twentyeight individuals declined to participate, $6 \%$ of those approached by the research team. Figure 1 summarises the numbers participating at different stages of the health check events.

Questionnaires were completed pre-and post-event by all participants (100\% completion rate). Fifteen managers completed questionnaires across the 21 events (one of them had responsibility for multiple sites and gave a single response in relation to these; two managers did not complete questionnaires). 
Table 1 Operationalisation of RE-AIM Dimensions and indicators used

Reach

Who participated, were they representative of the target population and were they a suitable population?

- $\quad$ Participant demographic characteristics

- Participant health information: perceived impact of work on health, previous experience of workplace health

Employee questionnaires checks

- Information on those who did not participate

Data collected at event

Effectiveness

Was the intervention successful, what was the impact of testing?

- $\quad$ Uptake of HIV tests, characteristics of those who had tests

Data collected at event Employee questionnaires

- Details of other health checks delivered

Data collected at event

- $\quad$ Reported employee learning from event

Employee questionnaires Manager questionnaires

- Information on acceptability and usefulness of HIV testing

Employee questionnaires Manager questionnaires

- Information on acceptability and usefulness of health checks

Employee questionnaires Manager questionnaires

Adoption

How successful was the intervention in recruiting the right companies/locations for the intervention?

- Summary data and representativeness of participating companies

Manager questionnaires

- Information about companies which were approached but did not participate

Interview with lead event organiser

- Recruitment processes and challenges

Interview with lead event organiser

Implementation

How, and how well, was the intervention delivered?

- Delivery of the intervention as intended

nterview with lead event organiser

- Experiences of attending the event

Employee questionnaires

- Views on the organisation of the event

Manager questionnaires

- Views on the scope of the event

Employee questionnaires Manager questionnaires

- $\quad$ Event costs

Interview with lead event organiser

- Online toolkit

Manager questionnaires

Maintenance

Has employer behaviour changed? How likely is that that they would participate again?

- Intention to include sexual health in future activities

Manager questionnaires

- Willingness to participate in future events

Manager questionnaires

\section{Reach}

Overall, health check participants were broadly representative of the wider construction workforce, with the main differences being a higher proportion of women in this sample, and a higher proportion of permanent workers. Workers largely considered themselves to be in good health. Many had never had a health check at work, and most considered that their work had an adverse impact on their health.

\section{Participant demographic characteristics}

Table 2 shows the details of those who participated in health checks. It also examines whether the participant 


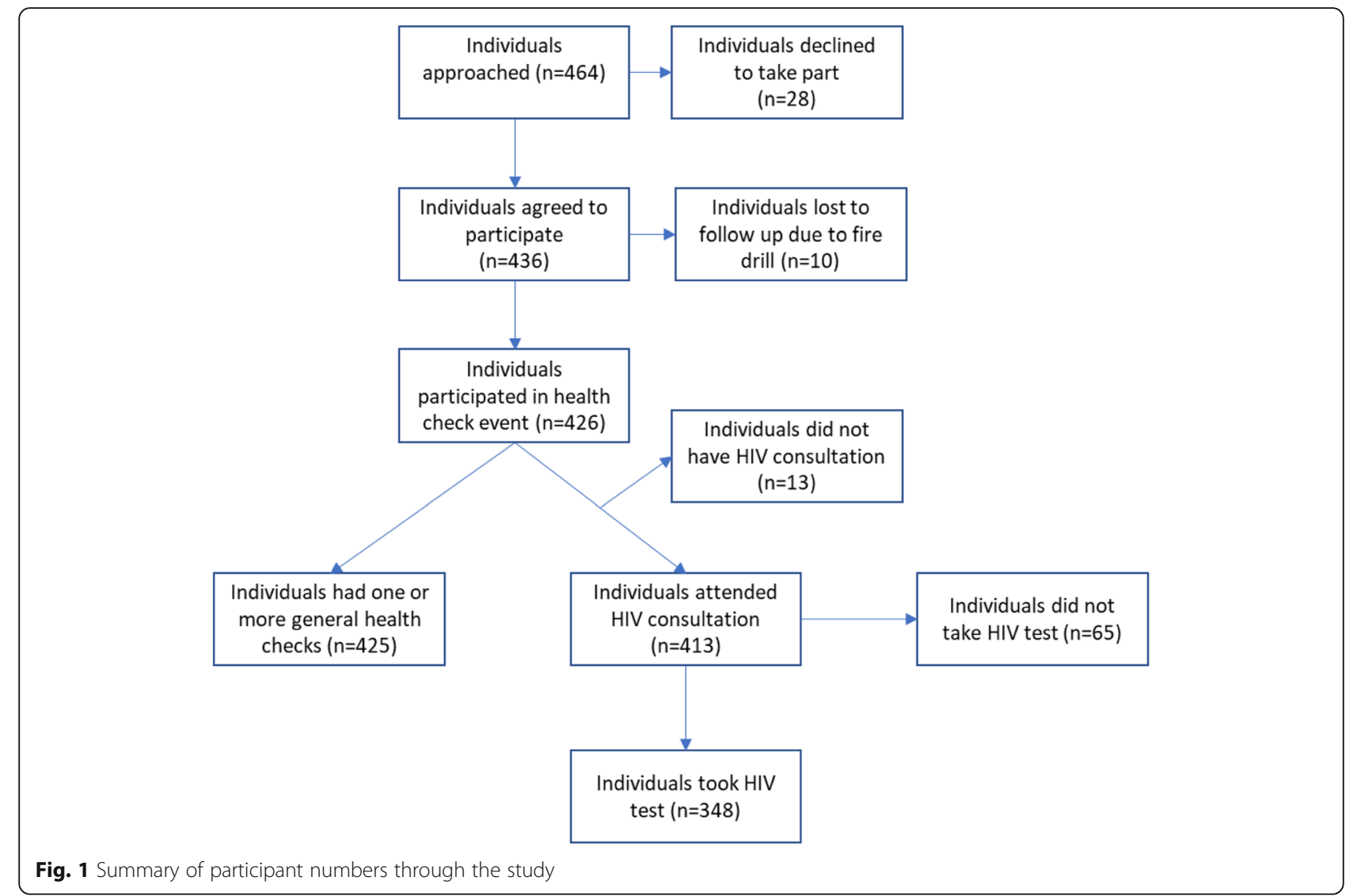

population was representative of the wider construction workforce.

Health check participants were representative of the wider construction workforce in terms of their ethnicity, age and whether English was their first language. There were more non-Europeans in the study sample than in the UK construction workforce overall $(p<0.001)$, but the proportions of UK versus non-UK workers did not differ significantly.

The 47 individuals who were born outside of the UK were from a total of 18 different countries, most commonly India $(n=11)$ and Jamaica $(n=4)$. Eleven individuals (6 men, 5 women) were born in a country where the prevalence of HIV is $0.5 \%$ or higher [81].

Participants were more likely than the wider construction workforce to be employed in permanent roles. There was weak evidence that participants were more likely to be heterosexual than the UK population in general - this may reflect reticence on this matter given the hegemonic masculinity evident in the construction sector [82]. The participant population had a higher proportion of women than the UK construction workforce, this is likely to reflect the fact that several study locations had a large administrative workforce as they were offices which were a work base for peripatetic tradespeople rather than being active construction sites.

Participants were not asked whether they lived away from home whilst they were working on this project, but they were asked to provide their home postcode. Six participants (out of 392 who answered the question) gave home postcodes which were over three hours' drive from the site and were therefore assumed to have been living away from home. A further four participants were living two hours' drive from the site. It is therefore estimated that up to $2.5 \%$ of participants could be classified as living away from home.

\section{Prior experience of health checks}

Participants were asked whether they had ever had a workplace health check before. Of 424 respondents, 181 reported that they had $(42.7 \%)$ and $57.3 \%$ had not. Likelihood of having had a health check at work increased with older age $(p<0.001)$; only $25.5 \%$ of those aged 30 years or below had previously had a health check at work. The likelihood of having had a 
Table 2 Demographic characteristics of health check participants

\begin{tabular}{|c|c|c|c|c|c|}
\hline & $\begin{array}{l}\text { Male } \\
n=348 \\
(81.7 \%)\end{array}$ & $\begin{array}{l}\text { Female } \\
n=78 \\
(18.3 \%)\end{array}$ & $\begin{array}{l}\text { Total } \\
n=426 \\
(100 \%)\end{array}$ & $\begin{array}{l}\text { UK construction workforce, for } \\
\text { comparison }\end{array}$ & $p$ \\
\hline & n (\%) & $\mathrm{n}(\%)$ & n (\%) & & \\
\hline \multirow[t]{2}{*}{ Gender } & & & & [75] & $p<0.001$ \\
\hline & $81.7 \%$ & $18.3 \%$ & & Male: $87.6 \%$; female: $12.4 \%$ & \\
\hline Age (years) & & & & {$[76]^{a}$} & $p=0.233$ \\
\hline $17-30$ & $90(25.9)$ & $16(20.5)$ & $106(24.9)$ & Age 16-24: 10\% & \\
\hline $31-40$ & $99(28.4)$ & $23(29.5)$ & $122(28.6)$ & Age $25-49$ : 61\% & \\
\hline $41-50$ & $85(24.4)$ & $18(23.1)$ & $103(24.2)$ & Age 50-64: 26\% & \\
\hline $51-70$ & $74(21.3)$ & $21(26.9)$ & $95(22.3)$ & Age $65+: 2 \%$ & \\
\hline Ethnicity & & & & [77] & $p=0.220$ \\
\hline White & $313(89.9)$ & $62(79.5)$ & $375(88)$ & White $87.7 \%$ & \\
\hline Mixed & $4(1.1)$ & $3(3.8)$ & $7(1.6)$ & Mixed $1.2 \%$ & \\
\hline Asian or Asian British & $22(6.3)$ & $5(6.4)$ & $27(6.3)$ & Asian/Asian British 6.6\% & \\
\hline Black or Black British & $7(2)$ & $6(7.7)$ & $13(3.1)$ & Black/Black British 3.0\% & \\
\hline Other ethnicity & $0(0)$ & $1(1.3)$ & $1(0.2)$ & Other $1.6 \%$ & \\
\hline Not stated & $2(0.6)$ & $1(1.3)$ & $3(0.7)$ & & \\
\hline Country of birth & & & & {$[27]$} & $p<0.001$ \\
\hline UK & 309 (88.8) & $63(80.8)$ & $372(87.3)$ & UK 90\% & \\
\hline Europe & $14(4.1)$ & $7(9.2)$ & $21(5)$ & Europe $7 \%$ & \\
\hline Rest of world & $20(5.8)$ & $6(7.9)$ & $26(6.2)$ & Rest of world $3 \%$ & \\
\hline Not stated & $5(1.4)$ & $2(2.6)$ & $7(1.6)$ & & \\
\hline English as first language & & & & $\mathrm{b}[78]$ & $p=0.231$ \\
\hline Yes & $326(93.7)$ & $71(91)$ & $397(93.2)$ & $92.3 \%$ & \\
\hline No & $19(5.5)$ & $7(9)$ & $26(6.1)$ & & \\
\hline Not stated & $3(0.9)$ & $0(0)$ & $3(0.7)$ & & \\
\hline Nature of employment & & & & [79] & $p<0.001$ \\
\hline Permanent & $230(66.1)$ & $64(82.1)$ & $294(73.7)$ & $\begin{array}{l}\text { Men } 56.2 \% \text {; women } 86.8 \% \\
\text { Total } 59.9 \%\end{array}$ & \\
\hline $\begin{array}{l}\text { Non-permanent (agency, contact, self- } \\
\text { employed, other) }\end{array}$ & $95(27.3)$ & $10(12.8)$ & $105(26.3 \%)$ & $\begin{array}{l}\text { Men } 43.8 \% \text {; women } 13.1 \% \\
\text { Total } 40.1 \%\end{array}$ & \\
\hline Not stated & $23(6.6)$ & $4(5.1)$ & $27(6.3)$ & & \\
\hline Sexual Orientation & & & & $\mathrm{b}[80]$ & $p=0.052$ \\
\hline Heterosexual & 337 (96.8) & $78(100)$ & $415(97.4)$ & Heterosexual 94.6\% & \\
\hline Homosexual & $2(0.6)$ & $0(0)$ & $2(0.5)$ & Homosexual $1.4 \%$ & \\
\hline Other & $2(0.6)$ & $0(0)$ & $2(0.5)$ & Other $1.5 \%$ & \\
\hline Not stated & $7(2)$ & $0(0)$ & $7(1.6)$ & & \\
\hline
\end{tabular}

${ }^{a}$ statistical comparison is against published data from the UK Annual Population Survey, this uses different age boundaries to this study

${ }^{b}$ comparison is with total UK population, not construction workforce

c the difference is significant for total population, and also for men only

health check at work also varied by nationality, with migrant workers from Europe being less likely (19\% reported a health check) and those from the rest of the world more likely (61.5\%) to report having had a workplace health check previously compared to nonmigrant workers $(p=0.014)$.

\section{Participant health}

The majority of participants reported themselves as being in good health - when asked 'how healthy do you feel now?', on a scale of $1-10$, the median score was 8 (interquartile range $7-8$ ), with $78.6 \%$ percent of responders scoring themselves at 7 or above, and $21.4 \%$ 
(91 individuals) scoring 6 or lower. Women reported worse health $($ median $=7)$ than men $($ median $=8),(p=$ 0.07). Permanent employees reported worse health (median $=7)$ than those that were non-permanent (median = 8) $(p=0.002)$, this difference persisted when the comparison was drawn for men only.

Participants were asked if work affected their health. Of 418 responses ( 8 missing), 22.5\% ( $n=94$ participants) reported that their work affected their health a lot and $59.3 \%(n=248)$ reported that it affected their health a little. The likelihood of reporting work-related health effects was higher for those who worked in permanent roles (252 workers, $87 \%$ of permanent workers who answered the question) compared to those who were nonpermanent (70 individuals, $68.6 \%$ of those answering) $(p<0.001)$. There were no other significant interactions.

Table 3 shows the main work-related health issues reported by participants.

Although Reach was not specifically addressed in the open questions, a small number of respondents commented on the importance of health checks for the construction population, either because of the nature of their health, or because they would not seek health care through other routes such as GPs, comments included: "This is a fantastic chance to have on-site as most men don't even bother with the doctors" (Male worker); and "Some people probably find it difficult to have time to get to the doctors" (H\&S manager).

\section{Who didn't participate?}

The total number of workers who were on site on each day and therefore entitled to participate could not be ascertained. Although managers were asked to confirm the size of the site workforce (this information is shown with company details in Additional file 4), most only gave figures for those who were directly employed and did not include workers who were subcontracted or selfemployed. Other sites were a base for peripatetic workers who attended briefly only at the beginning and end of the working day.

Most available appointments were filled at the events, although there were sometimes slow periods initially, particularly where advance promotion had been poor, followed by busier times as word spread. At some events, demand exceeded capacity, and additional events were arranged.

Twenty-eight individuals, at seven events, were approached by the research team but declined to participate in health checks. The most common reason given was being too busy $(n=14)$, this included three who were paid by work output (hence attendance would have had a financial impact). Other reasons given were having health checks elsewhere $(n=5)$, having unrelated health issues $(n=3)$ and perceiving they were too young to need a check $(n=2)$. At fourteen events, all appointments were allocated in advance of the event, so reasons for non-participation were not available.

\section{Effectiveness}

Overall, participation in HIV testing amongst those attending for health checks was very high. Acceptability of HIV testing in the workplace environment was very high, with benefits for both workers and employers reported. There was good agreement that guidance given was understandable and high confidence of making lifestyle changes following the event.

Table 3 Work related health issues reported by participants

\begin{tabular}{|c|c|c|c|}
\hline \multirow[t]{2}{*}{ Health effect reported } & \multicolumn{3}{|c|}{$\begin{array}{l}\text { Number of participants }(n=426)(\% \text { of health } \\
\text { check population) }\end{array}$} \\
\hline & $\begin{array}{l}\text { Work affects my } \\
\text { health a little }\end{array}$ & $\begin{array}{l}\text { Work affects my } \\
\text { health a lot }\end{array}$ & Total \\
\hline Stress, pressure and mental health & $80(18.8 \%)$ & $38(8.9 \%)$ & $\begin{array}{l}120 \\
(28.2 \%)\end{array}$ \\
\hline Musculoskeletal disorders, aches and pains & $44(10 \%)$ & $21(4.9 \%)$ & $\begin{array}{l}65 \\
(15.2 \%)\end{array}$ \\
\hline $\begin{array}{l}\text { Lifestyle impact e.g. overweight, sitting down too much, not being able to eat the right } \\
\text { food or exercise because of work }\end{array}$ & $28(6.6 \%)$ & $10(2.3 \%)$ & $\begin{array}{l}38 \\
(8.9 \%)\end{array}$ \\
\hline High workload & $16(3.7 \%)$ & $9(2.1 \%)$ & $\begin{array}{l}25 \\
(5.9 \%)\end{array}$ \\
\hline Tiredness or fatigue & $14(3.3 \%)$ & $7(1.6 \%)$ & $\begin{array}{l}21 \\
(4.9 \%)\end{array}$ \\
\hline Dust, breathing & $9(2.1 \%)$ & $1(0.2 \%)$ & $\begin{array}{l}10 \\
(2.3 \%)\end{array}$ \\
\hline Other work hazards e.g. noise, vibration & $3(0.7 \%)$ & $2(0.5 \%)$ & $5(1.2 \%)$ \\
\hline Positive impact of work & $2(0.5 \%)$ & $2(0.5 \%)$ & $4(0.9 \%)$ \\
\hline
\end{tabular}




\section{Participation in HIV testing}

Out of the 426 participants who attended for a health check, 413 (96.9\%) opted to have a consultation about sexual health and 348 (81.7\%) took an HIV test. Of those who took an HIV test, only 78 (22.4\% of those tested) had previously been tested, and only 22 (6.3\% of those tested) of these had been tested in the last 12 months. All HIV tests were non-reactive (negative). Eleven individuals were referred to a local sexual health clinic for further assessment or treatment.

No information was gathered on why participants declined a consultation about sexual health or an HIV test, as this information was available only to the sexual health teams to preserve participant confidentiality.

There were no differences in characteristics between participants who had an HIV consultation and those did not. Those who took an HIV test differed from those who did not in terms of age $(p=0.043)$. Participants aged 31-40 were more likely than other age groups to take an HIV test, this is shown in Table 4. There were no other significant interactions.

\section{Acceptability and impact of HIV testing}

Participants were asked whether they considered it acceptable to include HIV testing as part of a workplace event. Of the 421 participants who responded (5 missing), 408 (96.9\%) said it was acceptable, while 13 individuals (3.1\%) considered that it was not acceptable. Nevertheless, all 13 had chosen to attend the health check event, 11 of these thirteen individuals attended an optional HIV consultation at the event, and six then opted to take the HIV test.

The managers who had organised or overseen events were also asked about the acceptability of HIV testing in this context. All except one considered that it was acceptable. Reasons given included the potential to increase workers' knowledge in this area, and the fact that it was "Good to try to get rid of the stigma" (H\&S manager). The fact that uptake of HIV testing had been good was seen by several as confirming its value and acceptability, "as take-up was high, colleagues obviously felt it was needed" (Wellbeing manager).
One manager and two employees made negative comments about opt-in HIV testing at work, such as, "I don't feel this added value to the workers, the feedback was it felt awkward" (H\&S manager), and also raised concerns about privacy when being given results in the workplace.

\section{Acceptability, and impact of overall health check event}

Participants found the event to be a positive experience. In response to the question 'Did you feel that health information was given to you in a language and format that was easy to understand?' of the 424 who answered the question (2 missing responses), 421 (99.3\%) answered 'yes'. Also, out of 422 who answered the question 'Would you attend this kind of workplace health event again?" (4 missing), 419 (99.3\%) said they would, and only three $(0.7 \%)$ said they would not.

Further evidence of impact comes from responses to the question, 'Did you learn anything new about your health in this event?", 311 participants $(74 \%$ of those responding, 6 missing responses) confirmed that they had. The likelihood of this did not vary significantly by age, ethnicity, gender, being UK born or speaking English as a foreign language. When asked 'Do you intend to make any changes to the way you manage your health following this event?' 296 (70.1\%) participants confirmed that they did. Confidence that these changes were achievable was high, with a median score of 8 (IR 7-9) in response to the question, 'on a scale of 1-10 how confident are you that you can make these changes?' There were no significant differences between participant sub-groups in terms of their confidence in making changes.

Responses in the manager questionnaires supported these findings; $100 \%(n=15)$ agreed that the health check events had been useful and that the events had been appropriate in terms of content, activities and focus. Perceived benefits included the positive impact on employee knowledge, the potential for improved health or to have provided reassurance. Comments included, "it has provided them with useful health information that should help them keep their health under control" (Site manager); "It got all of the participants talking about

Table 4 Participants who opted for an HIV consultation and/or HIV test, by age

\begin{tabular}{|c|c|c|c|c|c|c|c|c|c|}
\hline \multirow[b]{3}{*}{ Age group } & \multirow[b]{3}{*}{$\mathbf{n}$} & \multicolumn{4}{|c|}{ Had HIV consultation } & \multicolumn{4}{|c|}{ Took HIV test } \\
\hline & & \multicolumn{2}{|l|}{ Yes } & \multicolumn{2}{|l|}{ No } & \multicolumn{2}{|l|}{ Yes } & \multicolumn{2}{|l|}{ No } \\
\hline & & Number & $\%$ & Number & $\%$ & Number & $\%$ & Number & $\%$ \\
\hline $17-30$ & 106 & 103 & 97.2 & 3 & 2.8 & 86 & 81.1 & 20 & 18.9 \\
\hline $31-40$ & 122 & 117 & 95.9 & 5 & 4.1 & 109 & 89.3 & 13 & 10.7 \\
\hline $41-50$ & 103 & 101 & 98.1 & 2 & 1.9 & 82 & 79.6 & 21 & 20.4 \\
\hline $51-70$ & 95 & 92 & 96.8 & 3 & 3.2 & 71 & 74.7 & 24 & 25.3 \\
\hline Total & 426 & 413 & 96.9 & 13 & 3.1 & 348 & 81.7 & 78 & 18.3 \\
\hline
\end{tabular}


health issues for the day" (H\&S manager); and, "it helps to raise the awareness of employee health and wellbeing for both our employees and subcontractors" (H\&S manager).

Several managers reflected on the willingness of employees to attend and how well received the event had been, for example that it had been "received very well from all operatives and staff that attended" (H\&S manager). Some also made comments about the positive benefits of the events for the employer. This was partly about being able to share information with other parts of the business, but there were also reputational benefits, and potential recognition through formal schemes for participating in the events, "From a site perspective it boosted site morale showing that we were supplying on site health checks, the checks also featured in our Considerate Constructors Audit and was considered an innovative activity due to the research element of the testing" (Site manager); and "(it) helped show we are supporting health awareness with the workforce" (H\&S manager).

\section{Adoption}

Overall, participating companies were mostly large or very large, and therefore are not representative of the construction landscape; although participants were also drawn from their sub-contractors who are likely to be smaller companies. Recruitment of companies was challenging and time consuming.

\section{Participating companies}

A total of 21 sites took part in the research, from ten companies. Two further companies had been recruited and had scheduled events, but these were cancelled due to the COVID-19 pandemic. Details of the companies/ sites which participated are presented in Additional file 4.

For all but one company, there were reports of existing health or wellbeing activities, including a combination of individual interventions, (health checks, health kiosks), team events ('tough mudder', charity events) and organisational programmes (mental health first aid, employee assistance programmes, private health care, health promotion such as smoking cessation, healthy eating). For two companies, occupational health resources were mentioned (but did not specify health surveillance). No companies included sexual health awareness or HIV testing in their existing wellbeing activities.

\section{Representativeness of companies}

Seven out of the ten companies participating in the research had over 1000 employees, fewer than $0.03 \%$ of UK construction companies are this size [83]. They are therefore not themselves typical of UK construction companies: $96 \%$ of UK construction companies employ fewer than fourteen workers. However, all workers on the study sites were eligible to participate in the research, including those employed by the lead company which was responsible for the site, and also those working on behalf of sub-contractors, which might be small to medium enterprises (SMEs), or micro-sized companies. Therefore the companies and their supply chain taken as a whole are likely to be more representative of the construction landscape than the named companies participating, although the data available do not allow this to be examined in detail.

The participant companies varied in terms of the proportion of their workforce which was female. Some employed fewer than $1 \%$ women on site, others were office-based locations and had a much higher proportion of female employees. Again, this is not representative of the wider construction sector, and is likely to account for the high proportion of female participants taking part in the research.

\section{Experiences of recruitment}

Initial recruitment was through email contact with companies which were identified through internet searches or from the UK Construction Index. Initially, the focus was specifically on construction companies, this was expanded to included construction-related companies to increase the scope, as the response rate was initially low. A total of ninety-six companies were approached to gain access to the twelve who agreed to participate (12.5\%) (events with two of these companies were cancelled due to the COVID-19 pandemic). The main challenge was gaining access to a named individual who had the responsibility and authority to discuss the research and most contacts stalled at this early stage. Commonly, initial contact points (such as an info@ email address) failed to pass a message on, or initial contacts were made and then a company representative declined to participate in further discussion.

In 21 companies, the lead researcher made contact successfully and explained the research, but the company decided not to proceed. The most common reasons given included perceived overlap between the research and general health checks already provided (six companies) - albeit none providing HIV testing; the company perceiving themselves to be too small (three companies); and the company not having active sites within the geographical area of the study (four companies). Four companies simply withdrew from discussions or stopped answering calls. The inclusion of HIV testing in the research was not discussed until companies had expressed a desire to participate. One raised some initial concerns about it, and required further supporting information, but was then happy to proceed. No other companies 
raised any issues or concerns about the inclusion of HIV testing.

Key learning during the recruitment phase included the value of persistence, and the importance of getting to the right person to secure the sites and events.

\section{Implementation}

Overall, implementation was successful, with all events being conducted as planned. The success of events was enabled by a high degree of flexibility at the planning stage and the skills of the health care staff involved.

All 21 events were delivered successfully, with general health checks and HIV tests provided at all. Three themes related to implementation were identified from the responses to open questions in the managers' and employees' post-event questionnaires.

\section{Event organisation}

Events were seen as being successful because they had been well planned in advance, with negotiation and flexibility between the researchers and the host site. It was identified as important that events were scheduled for times when the workforce were most available.For example, at those stages of the project when there were high numbers on site, allowing good participation. Arranging multiple visits to a site was another way of achieving this. "Our two visits were held at the perfect times, as the first caught our demolition operatives just before they were leaving site at the end of December, and the second visit then caught the new starting operatives in January giving a good range of responses from operatives in very different areas of the industry" (Site manager). One manager also commented on the benefit of scheduling to tie in with other motivators such as "postChristmas, back to work since the new year / new me" (H\&S manager). Ensuring capacity throughout the working day was also important to ensure that workers could attend without the event interfering too much with their usual duties.

Challenges encountered by the research team in running events were mostly linked to poor organisation on the part of the host company such as failing to book suitable rooms for testing or failing to promote the event to workers well in advance. Whilst inconvenient, these issues were always successfully resolved on the day.

\section{Positive experiences}

Workers who responded to an open question about whether there was anything else they would like to add commented mostly about their positive experiences of the event. In particular, they noted the efficiency and professionalism of the health check teams, their friendliness, and their knowledge and ability to make the topics understandable. Comments included that the event had been, "well delivered, friendly, knowledgeable" (Male worker); that staff "were friendly and made it all easy to understand" (Female worker); and even, "excellent staff, worth making the trip on my day off" (Male worker). Similar comments were made by managers.

\section{Testing scope}

The third theme identified was the scope of testing. Several managers commented that it would be useful to include additional tests, such as those for diabetes, cholesterol, body fat and lung capacity. This view was supported by participants, who were asked specifically if there were other health assessments they would be interested in for future events. Out of 415 who answered the question, 167 (40.2\%) answered 'yes'. The most popular tests to include in future events related to cholesterol (34 participants), diabetes (28 participants), and mental health issues (15 participants). There were also 15 requests for assessment related to specific work-related hazards such as hand arm vibration, noise and dust, and six related to musculoskeletal disorders.

\section{Online toolkit}

The managers were asked whether the Test@Work toolkit [66] had been a helpful resource. Those that answered this question (14/15) felt it had been useful. Some commented on how user-friendly it was, others on how it had enhanced their knowledge and awareness of workplace health promotion, health checks and HIV testing. Although the toolkit was designed to increase the managers' knowledge so that they could promote the health check event effectively with the workforce, some shared it directly with workers. Others shared it with other colleagues in the company to increase awareness more widely.

\section{Costs}

The direct costs of the overall health check were low, as volunteers gave their time free of charge. This involved a major effort to recruit, train and manage teams of volunteers attending each event, but also provided significant benefits for these healthcare trainee volunteers in terms of professional development [69]. The health check team spent a total of 107 person-days on work sites to deliver the 21 events (37 for HIV professionals, 70 for health check volunteers), with 3-7 people at each event. Equipment for health checks (e.g., sphygmomanometer, scales, height and waist measures) cost approximately $£ 300$. For HIV testing, the cost was nominally $£ 50$ per person tested (for test kit and staffing). On some sites, testing was funded by healthcare outreach services.

There were no direct charges to the construction sites for participating, but they had to absorb the opportunity costs of time when workers were attending the event 
rather than doing their usual jobs. Each individual attended the event for around $30-45 \mathrm{~min}$, although the time could increase if there was extra waiting time. No participating companies objected to this, although it was not clear whether the lost time was at the expense of the lead company or the sub-contractor. Three workers declined to attend because they were concerned about losing earnings as a result of reduced output for the day, and others might also have been discouraged from signing up to the programme for this reason, particularly those who were sub-contracting or self-employed. A small number of workers were initially reluctant to attend but did so once given reassurance that they would not be penalised.

\section{Maintenance}

Overall, there was a high willingness from companies to participate in future events which were arranged by an external partner. The likelihood of companies incorporating HIV awareness in their own events was limited by an organisational focus on other topics.

Managers who hosted events were asked whether they were planning to incorporate sexual health and HIV awareness in their own workplace health programmes in future as a result of their involvement in Test@Work. One organisation confirmed they had already taken action to implement change and five further organisations confirmed future implementation intentions -"Sexual health has now been added into our induction presentation in order to highlight its importance, we have also issued a toolbox talk on HIV awareness which was issued last month" (Site manager). Nine respondents were not planning to take the topic forward (two did not answer), this was generally because it did not fit with their company's pre-existing campaigns which were focused mostly on mental health. Some managers shared that they did not have the authority to make the decision as health programmes were planned centrally (e.g. organisational-level) rather than locally (site-level).

In terms of participation in future events, all managers who completed a post-event questionnaire confirmed that they would host such events again if there was an opportunity. Eight of the 10 companies involved in the research had already undertaken or committed to additional events before the project ended.

\section{Discussion}

\section{HIV testing in construction}

This study found opt-in HIV testing in UK construction workplaces to be very successful. HIV testing was acceptable to workers and uptake was high, with almost all workers at our health check events choosing to attend a sexual health consultation, and 8 in 10 opting in for an HIV test. This compares favourably with other HIV testing rates outside of traditional settings, such as workplaces in Africa and Afghanistan (67\%) [11], community settings in Europe (9-95\% testing uptake is reported, but most studies evaluated have uptake below $80 \%$ and provide incomplete data on numbers invited to test) [12], and new registrants at UK General Practices (45\% uptake of testing offer) [84]. The proportion who were being tested for the first time in our study (78\%), was far higher than reported in other community settings (e.g. $14 \%$ first time tests in a systematic review of testing in resource-rich countries) [12]. This is important, given the association between first time testing and higher rates of seropositivity [11].

No cases of HIV were identified by this study, but this does not negate the value of testing, particularly given the relatively small size of the study population. Seropositivity for HIV testing is $0.4 \%$ in UK community settings overall (with most testing targeting high risk groups such as MSM) [1], and has been reported at $0.2 \%$ in a cohort of new GP registrants [84]. The likelihood of case finding could be increased by targeting potentially higher risk construction populations, such as workers living in London or working on major projects. London construction projects employ four times as many European migrant workers and more than twice as many non-EU migrant workers compared to UK construction overall [27], with similar variations in ethnicity. During construction of the Olympic park for London 2012 for example, $24 \%$ of the workforce were of BAME ethnicity, compared to $7 \%$ of the UK construction workforce at that time [85]. Additionally, London based projects and mega projects are more likely to employ workers who are living away from their families $[29,86]$, with the associated risk behaviours reported in these populations $[30,87]$. The combination of high uptake of testing (as achieved in this study) with likelihood of higher prevalence of HIV would make this a valuable approach to identifying undiagnosed cases of HIV. Regular testing (e.g. every three years) has been identified as both desirable and cost effective even where incidence is as low as $0.01 \%$ pa [88], and annual testing is likely to be cost effective once prevalence reaches $0.8 \%$ [89].

It is worth noting that cases could have been identified in our sample after the health check events since workers who did not have an HIV test on the day were given information at the time about how to access free HIV testing at their convenience. Also, 291 construction workers from the Test@Work study (68.3\% of health check participants) signed up for an additional text messaging intervention called Test@Work Texts [90] that was delivered after their health check event, between March - June 2020 and during the COVID-19 pandemic when access to sexual health clinics was limited. Workers received a series of text messages promoting 
sexual health and HIV testing (as well as other areas of health) over a 10-week period, with subsequent textbased evaluation of the intervention. A small number of respondents reported having taken a further HIV test after the event. It is therefore possible that positive cases may have been identified in our sample outside of the health check event days.

Educating the workforce and raising awareness of the importance of HIV prevention and testing are important, as this could influence a far higher proportion of workers than can be reached through on-site testing. This could be addressed through further implementation of the Test@Work online toolkit [66] particularly if it can be introduced through major construction projects, companies or industry bodies. Individual sites can then follow this up by liaising with local testing providers through the healthcare services. Signposting to selftesting services might also be helpful in some circumstances [91]. As with onsite testing initiatives, educational interventions would be particularly valuable if they targeted those workplaces with a higher potential HIV prevalence. However, those who are most at risk of HIV might be the least likely to seek testing due to fear of negative consequences or stigma, particularly if there are concerns about being able to keep the diagnosis confidential at work. Design of interventions needs to take this into account.

\section{General health checks in construction}

HIV tests in this study were provided as part of a wider health check. This is recommended in the literature as a way of normalising HIV testing and reducing stigma [15, $60,92,93]$ - the high uptake of testing in this study supports this approach. The study also illustrated the direct benefits of offering these wider health checks. They were highly valued by workers who participated and managers who hosted them, with high levels of interest expressed towards arranging further events. Encouragingly, our data show that many workers planned to make lifestyle changes to improve their health and felt confident that they would be able to do so. This is important given the recognised poor health of the construction workforce [40, 46, 49], and the 'anti-health promoting' nature of the construction industry [94]. Although there are national health programmes which have a similar scope to the general health checks offered in our study, their uptake is often limited. For example, the UK National Health Service (NHS) health check is offered to those aged between 40 and 75 in the UK [95] but uptake is only just over $50 \%$ [96]; and uptake is lower amongst men and those at the younger end of the target range [97, 98]. A particular barrier to men participating in such programmes is lack of time to do so [99], making workplace events such as this especially helpful for this population.

However, there are also challenges when conducting health interventions in the construction sector. It is an industry which is highly fragmented, with extensive subcontracting, high levels of self-employment, and an excessive focus on cost [100]. In the current study, the majority of participating companies were extremely large and self-employed workers were underrepresented, only $26 \%$ of those seen were self-employed compared to $40 \%$ in the wider construction population. This mirrors the findings of Hanna et al. [94], that health promotion in construction is more likely to occur with large employers and those with greater numbers of directly employed workers, as others are unlikely to be able to see sufficient benefit to offset the costs.

Interventions like the one described here, which are open to all workers on site regardless of whether they work for the main contractor or its subcontractors, are one way of redressing this imbalance. This approach has been taken by UK mega projects such as London 2012 [101] and Heathrow Terminal 5 [102] to improve the health of workers through the supply chain. It can also help knowledge and good practices to 'trickle down' through the industry [103]. However, further efforts are needed to access those SMEs and micro-organisations that are not contracted on larger projects; and to improve access to health promotion for self-employed and agency workers who are paid on the basis of the measured work that they complete [104] and do not wish to lose working time.

Regardless of how successful health check events are, the likelihood of workers making long term changes to their lifestyle is influenced by the wider context including family, workplace and industry factors [105-107]. There was evidence of this in the current research, with participants making comments about the difficulties of healthy eating and exercise due to the constraints of work demands. Additionally, over $80 \%$ of participants considered that work had a direct adverse impact on their health. The most frequent conditions mentioned were musculoskeletal disorders and stress/mental health issues, which are the most prevalent work-related health problems reported in UK construction [108]. Any approach to improve worker health needs to take this context into account. For example, the Test@Work online toolkit [66] used successfully in this research to inform managers about the value of HIV testing could be developed further to highlight to employers the importance of structural measures to improve the health of their workforce, alongside measures that individuals might take themselves.

The non-HIV element of the Test@Work intervention focused specifically on general health, those factors 
which are typically influenced by lifestyle, such as stress, diet, exercise and smoking. However, some participants raised issues which were broader than this. For example, when asked what additional health checks would be valued, some mentioned tests of lung function, hearing or hand arm vibration syndrome. These are examples of health surveillance, which are a legal requirement for those who are exposed to particular work hazards. Although the number that specifically mentioned this was small, the fact that more than half of participants confirmed they had never had a workplace health check confirms the limited access to Occupational Health $(\mathrm{OH})$ services in this population. This is a known challenge. Across the UK, only 14-18\% of the workforce have access to $\mathrm{OH}$ services $[109,110]$. The proportion is typically even lower in construction, despite the higher health risks, due to the way the sector is configured and costed and the high proportion of SMEs $[111,112]$. General health checks to support lifestyle changes, and occupational health provision to address work related conditions are both important. It is important that employers and workers understand the difference, and recognise that one is not a substitute for the other. Again, this could be highlighted in revised versions of the online toolkit.

\section{Recommendations for future testing and additional interventions}

Recommendations for future events of this nature are summarised in Table 5.

\section{RE-AIM - value of structured evaluation}

Using the RE-AIM tool was an effective way of evaluating the intervention, particularly in considering the representativeness of participant individuals and companies. This helped to highlight the particular challenges of working in the construction sector, and how these might be addressed.

\section{Limitations and further research}

This study achieved its aim of delivering and evaluating opt-in HIV testing in construction workplaces; the similarities between participants and the wider UK construction workforce give confidence that the study sample was broadly representative of this population. However, because workers on a construction site typically come from a wide variety of companies and agencies, it was not possible to directly compare health check participants to others on site who chose not to attend. This makes it more difficult to understand the barriers to attending for HIV testing (and general health checks) in construction workplaces and how these might be overcome. Further work is in progress to explore this.
Table 5 Recommendations for future interventions

Recruiting companies for workplace health interventions

- It is important to identify named contacts when targeting companies. Local groups of H\&S professionals (such as IOSH in the UK) may offer a route for this, snowball recommendations between companies are also useful

- A greater focus on SMEs and micro-organisations is important, particularly those that do not work on major projects. They may be accessed through industry forums such as Working Well Together and Build UK

- It is important to improve access to workplace health promotion for self-employed workers, this might be achieved by offering appointments at the beginning and end of working days. Providing links to resources that can be accessed outside of work hours might also be important for this group e.g. online resources, self-testing opportunities or weekend/evening clinics

HIV testing in construction

- There is an expected benefit of targeting higher risk populations e.g. in major cities and on mega projects, where a greater proportion of workers may be from higher risk countries and/or living away from home and more likely to demonstrate high risk behaviours

- $\quad$ Events must be planned to ensure reactive results can be sensitively and discreetly managed, and to demonstrate to participants that this can happen

- Options should be available for individuals to have testing independently after the event if they prefer

- Wider promotion through the sector is needed to get sexual health and HIV on the agenda of major organisations and projects and the industry more widely

- HIV testing could be driven by outreach from public health services, to enable central funding of testing

Providing general health checks

- Events should be planned to coordinate with and promote existing $\mathrm{OH}$ arrangements

- The 'volunteer' model for health check delivery proved very successful, and reduces costs of health checks, but carries high administrative, supervisory and support requirements

- Health checks could be expanded to include tests such as cholesterol and diabetes which are part of the NHS health check in the UK

Test@Work online toolkit

- Education of managers is useful to raise awareness of HIV, so that they can inform and support their workforce and promote testing

- A separate resource for workers provided in advance of health checks would be useful e.g. a one-page document or online resources

- There is an opportunity to remind employers of their legal obligations in respect of occupational health checks in addition to general health checks which focus on lifestyle factors

- There is an opportunity to educate employers on the importance of organisational changes to improve worker health and support lifestyle changes

\section{Conclusions}

Test@Work is the first study to deliver and evaluate opt-in HIV testing in the UK construction sector. We found strong evidence that HIV testing can be implemented successfully through construction workplaces, with high uptake and high numbers of first-time tests 
compared to other community settings. Further studies are required to confirm whether the prevalence of HIV in this population make testing of this nature an effective and cost-effective approach. Testing would have the most impact if it targeted companies with more highrisk workers e.g. those in major cities or on megaprojects.

There was strong evidence regarding the desire for and acceptability of general health checks for this population, despite initial challenges in negotiating access within organisations. Testing was largely conducted on sites run by very large companies. This illustrates the importance of this route to access the wider construction workforce given the fragmented nature of the sector, but other approaches are also needed to reach workers in small and micro companies, and those which do not work on major projects.

Education regarding HIV testing and general health risks are important to support workplace testing initiatives. The Test@Work online toolkit was a useful approach and could be further developed to ensure employers are aware of the wider obligations and opportunities in respect of worker health.

Finally, given the high levels of acceptability of HIV testing in the workplace, our study suggests that this is an approach that may also be particularly valuable in countries with higher HIV prevalence rates in the general population.

\section{Abbreviations \\ ART: Antiretroviral therapy; BAME: Black, Asian and minority ethnic; BMI: Body Mass Index; CCGs: Clinical Commissioning Groups; EEA: European Economic \\ Area; EU: European Union; GP: General Practitioner (family doctor); MSM: Men who have sex with men; H\&S: Health and Safety; HIV: Human \\ Immunodeficiency Virus; NHS: National Health Service; PHQ-2: Patient Health Questionnaire-2 item; SME: Small and Medium sized Enterprises (typically fewer than 250 employees); UK: United Kingdom; WHO: World Health Organization}

\section{Supplementary Information}

The online version contains supplementary material available at https://doi. org/10.1186/s12889-021-11739-z.

Additional file 1. Participant pre-and post-event questionnaires.

Additional file 2. Manager pre-and post-event questionnaires.

Additional file 3. Sexual Health_HIV Consultation Recording Sheet.

Additional file 4. Details of companies and sites visited.

\section{Acknowledgements}

We would like to thank the wider health check team, in particular peer mentors: Sala Khulumula and Susan Tate; John McLuskey for supporting the inaugural training session; Fiona Moffatt for supporting a health check event, the community HIV testing teams; Judith Green and team, Salim Khalifa, Makinder Chahal, and the organisations providing the host sites for our health check events.

\section{Authors' contributions}

$\mathrm{HB}$ conceived the project, secured funding (with $\mathrm{CE}$ ), designed the research and reviewed and edited the paper. CE co-designed the research, reviewed and edited the paper. SS undertook data collection and data management. WJ analysed the data and drafted the manuscript. MM and KW co-delivered the intervention and training for the health promotion team. All authors have read and agreed to the published version of the manuscript.

\section{Funding}

The Test@Work study was funded by Gilead Sciences, Inc. (Grant Reference Number-Blake: INUK276 5347HIVDVE). The sponsors had no involvement in the study design, the collection, analysis and interpretation of data, or the preparation of the article.

\section{Availability of data and materials}

The Test@Work study does not have ethical approval to share the study dataset for reasons of participant confidentiality. Some of the study data may be available from the corresponding author on reasonable request.

\section{Declarations}

Ethics approval and consent to participate

Attending an HIV consultation was an optional element of the health check (attendance at the health check was also voluntary). All individuals who had a consultation were then given further detailed information before they gave informed consent if they wished to proceed to testing. Informed consent to participate in the research was obtained from all participants. The study had approval from the University of Nottingham Faculty of Medicine and Health Sciences Research Ethics Committee (Ref: FMHS LT12042016, amend no 2: 05112018).

\section{Consent for publication}

Not applicable.

\section{Competing interests}

The authors declare no competing interest. The funders had no role in the design of the study; in the collection, analyses, or interpretation of data; in the writing of the manuscript, or in the decision to publish the results.

\section{Author details}

${ }^{1}$ School of Health Sciences, University of Nottingham, Nottingham, UK. ${ }^{2}$ School of Medicine, University of Nottingham, Nottingham, UK. ${ }^{3} \mathrm{NIHR}$ Nottingham Biomedical Research Centre, Nottingham, UK.

Received: 10 March 2021 Accepted: 29 August 2021

Published online: 24 September 2021

References

1. O'Halloran C, Sun S, Nash S, Brown A, Croxford S, Connor N, et al. HIV in the United Kingdom: Towards Zero 2030. 2019 report. Public Health England, London.; 2019.

2. Gheibi Z, Shayan Z, Joulaei H, Fararouei M, Beheshti S, Shokoohi M. Determinants of AIDS and non-AIDS related mortality among people living with HIV in Shiraz, southern Iran: a 20-year retrospective follow-up study. BMC Infectious Diseases. 2019;19(1).

3. Harb AK, Logan L, Guerra L. national HIV self-sampling service November 2017 to October 2018. Public Health England; 2019.

4. Hernando V, Alvárez-del Arco D, Alejos B, Monge S, Amato-Gauci AJ, Noori T, et al. HIV infection in migrant populations in the European Union and European economic area in 2007-2012: an epidemic on the move. JAIDS J= Acquired Immune Deficiency Syndromes. 2015;70(2):204-11. https://doi. org/10.1097/QAl.0000000000000717.

5. Alvarez-del Arco D, Fakoya I, Thomadakis C, Pantazis N, Touloumi G, Gennotte A-F, et al. High levels of postmigration HIV acquisition within nine European countries. Aids. 2017;31(14):1979-88. https://doi.org/10.1097/QAD. 0000000000001571

6. Fakoya I, Álvarez-Del Arco D, Monge S, Copas AJ, Gennotte A-F, Volny-Anne A, et al. HIV testing history and access to treatment among migrants living with HIV in Europe. J Int AIDS Soc. 2018;21:e25123. https://doi.org/10.1002/ jia2.25123.

7. Pebody R. First HIV home test approved for sale in UK: aidsmap; 2015; Available from: https://www.aidsmap.com/news/apr-2015/first-hiv-hometest-approved-sale-uk. [accessed 24 February 2021]. 
8. Witzel TC, Eshun-Wilson I, Jamil MS, Tilouche N, Figueroa C, Johnson CC, et al. Comparing the effects of HIV self-testing to standard HIV testing for key populations: a systematic review and meta-analysis. BMC Med. 2020; 18(1).

9. Lorenc T, Marrero-Guillamon I, Aggleton P, Cooper C, Llewellyn A, Lehmann $A$, et al. Promoting the uptake of HIV testing among men who have sex with men: systematic review of effectiveness and cost-effectiveness. Sex Transm Infect. 2011;87(4):272-8. https://doi.org/10.1136/sti.2010.048280.

10. Shrestha RK, Clark HA, Sansom SL, Song B, Buckendahl H, Calhoun CB, et al. Cost-Effectiveness of Finding New HIV Diagnoses Using Rapid HIV Testing in Community-Based Organizations. Public Health Reports. 2008;123(3_suppl): 94-100.

11. Suthar AB, Ford N, Bachanas PJ, Wong VJ, Rajan JS, Saltzman AK, et al. Towards universal voluntary HIV testing and counselling: a systematic review and Meta-analysis of community-based approaches. PLoS Med. 2013; 10(8):e1001496. https://doi.org/10.1371/journal.pmed.1001496.

12. Thornton A, Delpech V, Kall M, Nardone A. HIV testing in community settings in resource-rich countries: a systematic review of the evidence. HIV Med. 2012;13(7):416-26. https://doi.org/10.1111/j.1468-1293.2012.00992.x.

13. Croxford S, Tavoschi L, Sullivan A, Combs L, Raben D, Delpech V, et al. HIV testing strategies outside of health care settings in the European Union (EU)/European economic area (EEA): a systematic review to inform European Centre for Disease Prevention and Control guidance. HIV Med. 2020;21(3):142-62. https://doi.org/10.1111/hiv.12807.

14. Bowen P, Govender R, Edwards P, Cattell K. HIV testing of construction workers in the Western cape. S Africa AIDS Care. 2015;27(9):1150-5. https:// doi.org/10.1080/09540121.2015.1032877.

15. Muwanguzi PA NT, Kiwanuka N, Nelson LE, Nasuuna EM, Osingada CP, Nabunya R, Nakanjako D, Sewankambo NK. Effects of Workplace-based HIV Self-testing on Men's (WISe-Men) Uptake of Testing and Linkage to Posttest Services in Uganda: Protocol for a Cluster Randomized Trial. JMIR Research Protocols 30/12/2020:25099 (forthcoming/in press).

16. Chatora B, Chibanda H, Kampata L, Wilbroad M. HIV/AIDS workplace policy addressing epidemic drivers through workplace programs. BMC public health. 2018;18(1).

17. Corbett EL, Makamure B, Cheung YB, Dauya E, Matambo R, Bandason T, et al. HIV incidence during a cluster-randomized trial of two strategies providing voluntary counselling and testing at the workplace. Zimbabwe Aids. 2007;21(4):483-9. https://doi.org/10.1097/QAD.0b013e3280115402.

18. Weihs M, Meyer-Weitz A. Barriers to workplace HIV testing in South Africa: a systematic review of the literature. AIDS Care. 2016;28(4):495-9. https://doi. org/10.1080/09540121.2015.1109586.

19. Bowen P, Edwards P, Simbayi L, Cattell K. Hiv/aids interventions by construction firms in the Western cape, South Africa: a thematic analysis of qualitative survey data. Int J Constr Manag. 2013;13(4):11-33. https://doi. org/10.1080/15623599.2013.10878227.

20. Bowen $\mathrm{P}$, Govender R, Edwards $\mathrm{P}$, Lake A. HIV infection in the south African construction industry. Psychol, Health Med. 2018;23(5):612-8. https://doi. org/10.1080/13548506.2017.1380836.

21. Bowen P, Cattell K, Edwards PJ, Marks J. Perceptions of HIV/AIDS policies and treatment programmes by Western cape construction firms. Constr Manag Econ. 2010;28(9):997-1006. https://doi.org/10.1080/01446193.2010.4 95987.

22. Weine SM, Kashuba AB. Labor migration and HIV risk: a systematic review of the literature. AIDS Behav. 2012;16(6):1605-21. https://doi.org/10.1007/s104 61-012-0183-4

23. Blake $H$, Banerjee A, Evans C. Employer attitudes towards general health checks and HIV testing in the workplace. Public Health. 2018;156:34-43. https://doi.org/10.1016/j.puhe.2017.12.004.

24. Blake $H$, Hussain B, Hand J, Juma A, Evans C. Employers' views of the "healthy hub roadshow": a workplace HIV testing intervention in England. AIDS Care. 2019;31(2):181-5. https://doi.org/10.1080/09540121.2018.1500010.

25. Blake H, Hussain B, Hand J, Rowlands D, Juma A, Evans C. Employee perceptions of a workplace HIV testing intervention. Int J Workplace Health Manag. 2018;11(5):333-48. https://doi.org/10.1108/IJWHM-03-2018-0030.

26. Bowen $\mathrm{P}$, Govender R, Edwards P. Validating survey measurement scales for AIDS-related knowledge and stigma among construction workers in South Africa. BMC Public Health. 2016;16(1):70. https:/doi.org/10.1186/s12889-016-2756-z.

27. Hayter C. Migrant labour force within the construction industry. Office of National Statistics; 2018.
28. Waterman L. London 2012: occupational health in the construction programme. J R Soc Promot Health. 2007;127(3):113-8. https://doi.org/10.11 77/1466424007077343

29. EDF Energy. Hinkley point C environmental statement Vol 4 Bridgewater C: EDF Energy; 2011; Available from: https://www.umweltbundesamt.at/filea dmin/site/themen/energie/kernenergie/verfahren/uk/uvp_hinkleypoint/04_ envstatement/4_5_1.pdf. [accessed 15 February 2021].

30. O'Riain E, Spillane J, Sherratt F, editors. Healthy, Happy Workers? The Consequences of Commuting Between Northern Ireland and Great Britain. Proceedings of the 34th Annual ARCOM Conference; 2018.

31. Sweileh WM. Global output of research on the health of international migrant workers from 2000 to 2017. Global Health. 2018;14(1).

32. Ompad DC, Gershon RR, Sandh S, Acosta P, Palamar JJ. Construction trade and extraction workers: a population at high risk for drug use in the United States, 2005-2014. Drug Alcohol Depend. 2019;205:107640. https://doi.org/1 0.1016/j.drugalcdep.2019.107640.

33. DM B, RN L. He CBHSQ report: Bush DM, Lipari RN, substance Use and Substance Use Disorder by Industry. In:The CBHSQ Report, Rockville (MD): Substance Abuse and Mental Health Services Administration (US) 2015. Rockville; 2015.

34. Coggon D, Harris EC, Brown T, Rice S, Palmer KT. Occupation and mortality related to alcohol, drugs and sexual habits. Occup Med. 2010;60(5):348-53. https://doi.org/10.1093/occmed/kqq040.

35. Flannery J, Ajayi SO, Oyegoke AS. Alcohol and substance misuse in the construction industry. Int J Occup Saf Ergon. 2019:1-16.

36. Considerate Constructors Scheme. Spotlight on... drugs and alcohol: CCS; 2020; Available from: https://www.ccscheme.org.uk/publications/ spotlighton/drugsandalcohol/. [accessed 17 February 2021].

37. Boal WL, Li J, Dong XS, Sussell A. Health Risk Behavior Profile of Construction Workers, 32 States, 2013-2016. J Occup Environ Med 2020.

38. Strickland JR, Wagan S, Dale AM, Evanoff BA. Prevalence and perception of risky health behaviors among construction workers. J Occup Environ Med. 2017;59(7):673-8. https://doi.org/10.1097/JOM.0000000000001051.

39. Peters S, Grant M, Rodgers J, Manjourides J, Okechukwu C, Dennerlein J. A cluster randomized controlled trial of a Total worker health ${ }^{\oplus}$ intervention on commercial construction sites. Int J Environ Res Public Health. 2018;15(11): 2354. https://doi.org/10.3390/ijerph15112354.

40. Viester L, Verhagen EALM, Bongers PM, Van Der Beek AJ. Effectiveness of a worksite intervention for male construction workers on dietary and physical activity behaviors, body mass index, and health outcomes: results of a randomized controlled trial. Am J Health Promot. 2018;32(3):795-805. https://doi.org/10.1177/0890117117694450.

41. Chan APC, Nwaogu JM, Naslund JA. Mental ill-health risk factors in the construction industry: systematic review. J Constr Eng Manag. 2020;146(3): 04020004. https://doi.org/10.1061/(ASCE)CO.1943-7862.0001771.

42. Burki T. Mental health in the construction industry. Lancet Psychiatry. 2018; 5(4):303. https://doi.org/10.1016/S2215-0366(18)30108-1.

43. Kotera Y, Green P, Sheffield D. Work-life balance of UK construction workers: relationship with mental health. Constr Manag Econ. 2020;38(3):291-303. https://doi.org/10.1080/01446193.2019.1625417.

44. Waite L. In practice. Perspectives in public health 2012;132(2):56, https://doi. org/10.1177/1757913912437665.

45. Wilkinson RG, Marmot M. Social determinants of health: the solid facts: World Health Organization; 2003.

46. Väisänen D, Kallings LV, Andersson G, Wallin P, Hemmingsson E, Ekblom-Bak E. Lifestyle-associated health risk indicators across a wide range of occupational groups: a cross-sectional analysis in 72,855 workers. BMC Public Health. 2020;20(1)

47. Sherratt F. Shaping the discourse of worker health in the UK construction industry. Constr Manag Econ. 2018;36(3):141-52. https://doi.org/10.1080/ 01446193.2017.1337916.

48. HSE. Construction health risks: Key points - Managing occupational health risks in construction: Health and Safety Executive; 2021; Available from: https://www.hse.gov.uk/construction/healthrisks/key-points.htm. [accessed 24 February 2021]

49. Thabit H, Burns N, Shah S, Brema I, Crowley V, Finnegan F, et al. Prevalence and predictors of diabetes and cardiometabolic risk among construction workers in Ireland: the construction workers health trust screening study. Diabet Vasc Dis Res. 2013;10(4):337-45. https://doi.org/10.1177/14791641134 79808. 
50. Järvholm B, Stattin M, Robroek SJ, Janlert U, Karlsson B, Burdorf A. Heavy work and disability pension-a long term follow-up of Swedish construction workers. Scand J Work Environ Health. 2014;40(4):335-42. https://doi.org/10.5271/sjweh.3413.

51. Lemasters G, Bhattacharya A, Borton E, Mayfield L. Functional impairment and quality of life in retired Workers of the Construction Trades. Exp Aging Res. 2006;32(2):227-42. https://doi.org/10.1080/03610730600554065.

52. Arndt V. Construction work and risk of occupational disability: a ten year follow up of 14474 male workers. Occup Environ Med. 2005;62(8):559-66. https://doi.org/10.1136/oem.2004.018135.

53. Ajslev JZN, Lund HL, Møller JL, Persson R, Andersen LL. Habituating pain: questioning pain and physical strain as inextricable conditions in the construction industry. Nord J Work Life Stud. 2013;3(3):195-218. https://doi. org/10.19154/njwls.v3i3.3018.

54. Brenner $H$, Ahern W. Sickness absence and early retirement on health grounds in the construction industry in Ireland. Occup Environ Med. 2000; 57(9):615-20. https://doi.org/10.1136/oem.57.9.615.

55. Chung J, Wong B, Yan V, Chung L, So H, Chan A. Cardiovascular health of construction Workers in Hong Kong: a cross-sectional study. Int J Environ Res Public Health. 2018;15(6):1251. https://doi.org/10.3390/ijerph15061251.

56. Eaves S, Gyi DE, Gibb AG. Building healthy construction workers: their views on health, wellbeing and better workplace design. Appl Ergon. 2016;54:108. https://doi.org/10.1016/j.apergo.2015.11.004

57. Drake C, Haslam R, Haslam C. Facilitators and barriers to the protection and promotion of the health and safety of older workers. Policy and Practice in Health and Safety. 2017;15(1):4-18. https://doi.org/10.1080/14773996.2017.12 89453.

58. Gibb A, Drake C, Jones, W. Costs of occupational ill-health in construction: Institution of Civil Engineers; 2018; Available from: https://www.ice.org.uk/ ICEDevelopmentWebPortal/media/Documents/Disciplines\%20and\%2 OResources/Briefing\%20Sheet/Costs-of-occupational-ill-health-inconstructionformattedFINAL.pdf. [accessed 18 February 2021]

59. Build UK. Shortage occupations in construction: a cross-industry research report: build UK; 2019; Available from: https://builduk.org/wp-content/uploa ds/2019/01/Shortage-Occupations-in-Construction-A-cross-industry-researchreport-January-2019.pdf. [accessed 15 December 2020].

60. Ishimaru T, Wada K, Smith DR. HIV testing and attitudes among the working-age population of Japan: annual health checkups may offer an effective way forwards. Ind Health. 2016;54(2):116-22. https://doi.org/10.24 86/indhealth.2015-0087.

61. Glasgow RE, Vogt TM, Boles SM. Evaluating the public health impact of health promotion interventions: the RE-AIM framework. Am J Public Health. 1999;89(9):1322-7. https://doi.org/10.2105/AJPH.89.9.1322.

62. Glasgow RE, Harden SM, Gaglio B, Rabin B, Smith ML, Porter GC, et al. REAIM planning and evaluation framework: adapting to new science and practice with a 20-year review. Front Public Health. 2019;7. https://doi.org/1 0.3389/fpubh.2019.00064

63. Kessler RS, Purcell EP, Glasgow RE, Klesges LM, Benkeser RM, Peek CJ. What does it mean to "employ" the RE-AIM model? Eval Health Prof. 2013;36(1): 44-66. https://doi.org/10.1177/0163278712446066.

64. Gaglio B, Shoup JA, Glasgow RE. The RE-AIM framework: a systematic review of use over time. Am J Public Health. 2013;103(6):e38-46. https://doi.org/1 0.2105/AJPH.2013.301299.

65. Holtrop JS, Rabin BA, Glasgow RE. Qualitative approaches to use of the REAIM framework: rationale and methods. BMC Health Services Res. 2018;18(1).

66. Blake H, Somerset S, Evans C. Development and Fidelity testing of the test@work digital toolkit for employers on workplace health checks and opt-in HIV testing. Int J Environ Res Public Health. 2020;17(1):379. https://doi. org/10.3390/ijerph17010379.

67. Kroenke K, Spitzer RL, Williams JB. The patient health Questionnaire-2: validity of a two-item depression screener. Med Care. 2003;41(11):1284-92. https://doi.org/10.1097/01.MLR.0000093487.78664.3C.

68. Health Education England. Making Every Contact Count (MECC): Health Education England; 2021; Available from: https://www.makingeveryconta ctcount.co.uk/. [accessed 24 February 2021].

69. Blake H, Somerset S, Whittingham K, Middleton M, Yildirim M, Evans C. WHIRL study: workplace health Interprofessional learning in the construction industry. Int J Environ Res Public Health. 2020;17(18):6815. https://doi.org/10.3390/ijerph17186815.

70. WHO/UNAIDS. WHO, UNAIDS statement on HIV testing services: new opportunities and ongoing challenges Geneva: UNAIDS; 2021; Available from: https://www.unaids.org/en/resources/documents/2017/2017_WHOUNAIDS_statement_HIV-testing-services. [accessed 19 February 2021].

71. Pallant J. Survival manual. 7th edition ed. Abingdon, Oxford: Routledge; 2020, https://doi.org/10.4324/9781003117452.

72. Hsieh H-F, Shannon SE. Three approaches to qualitative content analysis. Qual Health Res. 2005;15(9):1277-88. https:/doi.org/10.1177/1049732305276687.

73. Braun V, Clarke V. Using thematic analysis in psychology. Qual Res Psychol. 2006;3(2):77-101. https://doi.org/10.1191/1478088706qp063oa.

74. Nowell LS, Norris JM, White DE, Moules NJ. Thematic analysis. Int J Qual Methods. 2017;16(1):160940691773384. https://doi.org/10.1177/1609406917733847.

75. ONS. EMP13: Employment by industry - Office for National Statistics: Office of National Statistics; 2021; Available from: https:/www.ons.gov.uk/ employmentandlabourmarket/peopleinwork/employmenta ndemployeetypes/datasets/employmentbyindustryemp132021].

76. DWP. Statistics on older workers by sector: Department for Work and Pensions; 2015; Available from: https://assets.publishing.service.gov.uk/ government/uploads/system/uploads/attachment_data/file/412033/olderworkers-by-sector-ad-hoc-statistics.pdf. [accessed 24 February 2021].

77. Gov.uk. Ethnicity facts and figures Employment by sector May 2020; Available from: https://www.ethnicity-facts-figures.service.gov.uk/work-pay-a nd-benefits/employment/employment-by-sector/latest\#download-the-data. [accessed 24 February 2021].

78. Gov.uk. Ethnicity facts and figures English language skills 2018; Available from: https://www.ethnicity-facts-figures.service.gov.uk/uk-population-by-ethnicity/ demographics/english-language-skills/latest. [accessed 24 February 2021].

79. ONS. EMP14: Employees and self-employed by industry - Office for National Statistics: Office for National Statistics; 2021; Available from: https://www. ons.gov.uk/employmentandlabourmarket/peopleinwork/employmenta ndemployeetypes/datasets/employeesandselfemployedbyindustryemp14. [accessed 24 February 2021].

80. ONS. Sexual orientation, UK:2018: Office for National Statistics Annual Population Survey; 2021; Available from: https://www.ons.gov.uk/ peoplepopulationandcommunity/culturalidentity/sexuality/bulletins/sexua lidentityuk/2018. [accessed 24 February 2021].

81. CIA. Country Comparisons HIV/AIDS - adult prevalence rate: CIA; 2021; Available from: https://www.cia.gov/the-world-factbook/field/hiv-aids-adultprevalence-rate/country-comparison. [accessed 24 February 2021].

82. lacuone D. "real men are tough guys": hegemonic masculinity and safety in the construction industry. J Men's Stud. 2005;13(2):247-66. https://doi.org/1 $0.3149 /$ jms.1302.247.

83. ONS. Construction statistics annual tables 2021; Available from: https://www ons.gov.uk/businessindustryandtrade/constructionindustry/datasets/ constructionstatisticsannualtables. [accessed 24 February 2021].

84. Leber W, McMullen H, Anderson J, Marlin N, Santos AC, Bremner S, et al. Promotion of rapid testing for HIV in primary care (RHIVA2): a clusterrandomised controlled trial. Lancet HIV. 2015;2(6):e229-e35. https://doi.org/1 0.1016/S2352-3018(15)00059-4.

85. Pascutto N. Equality \& Diversity Strategy - Crossrail learning legacy: Crossrail; 2016; Available from: https://learninglegacy.crossrail.co.uk/documents/equa lity-diversity-strategy/. [accessed 15 December 2020].

86. Green B. The real face of construction 2020 socio-economic analysis of the true value of the built environment. Chartered Institute of Building: Bracknell; 2020

87. Oswald D, Turner M, Editors. Exploring health and well-being of workers on a large multinational construction project. Proc, CRIOCM Conf: Advancement of Construction Management and Real Estate Edited by KW Chau, IYS Chan, W Lu, and C Webster; 2017.

88. Lucas A, Armbruster B. The cost-effectiveness of expanded HIV screening in the United States. Aids. 2013;27(5):795-801. https://doi.org/10.1097/QAD. Ob013e32835c54f9.

89. Baggaley RF, Irvine MA, Leber W, Cambiano V, Figueroa J, McMullen H, et al. Cost-effectiveness of screening for HIV in primary care: a health economics modelling analysis. Lancet HIV. 2017;4(10):e465-e74. https://doi.org/10.1016/ S2352-3018(17)30123-6.

90. Middleton M, Somerset S, Evans C, Blake H. Test@work texts: Mobile phone messaging to increase awareness of HIV and HIV testing in UK construction employees during the COVID-19 pandemic. Int J Environ Res Public Health. 2020;17(21):7819. https://doi.org/10.3390/ijerph17217819.

91. Public Health England. Freetesting HIV | Free HIV Kits for Self-testing at Home 2021; Available from: https://freetesting.hiv/. [accessed 25 February 2021]. 
92. Flowers P, Knussen C, Li J, McDaid L. Has testing been normalized? An analysis of changes in barriers to HIV testing among men who have sex with men between 2000 and 2010 in Scotland. UK HIV Medicine. 2013;14(2): 92-8. https://doi.org/10.1111/j.1468-1293.2012.01041.x.

93. Thapa S, Hannes K, Cargo M, Buve A, Peters S, Dauphin S, et al. Stigma reduction in relation to HIV test uptake in low- and middle-income countries: a realist review. BMC public health. 2018;18(1).

94. Hanna Esmée S, Markham S. Constructing better health and wellbeing? Understanding structural constraints on promoting health and wellbeing in the UK construction industry. Int J Workplace Health Manag. 2019;12(3):14659. https://doi.org/10.1108/IJWHM-03-2018-0031.

95. Hylton K, Thompson K, Kearney M, Lagord C. NHS Health Check - National guidance. 2019. Contract No.: February 242021.

96. Patel R, Barnard S, Thompson K, Lagord C, Clegg E, Worrall R, et al. Evaluation of the uptake and delivery of the NHS Health Check programme in England, using primary care data from 9.5 million people: a crosssectional study. BMJ Open. 2020;10(11):e042963.

97. Attwood S, Morton K, Sutton S. Exploring equity in uptake of the NHS health check and a nested physical activity intervention trial. J Public Health. 2016;38(3):560-8. https://doi.org/10.1093/pubmed/fdv070.

98. Martin A, Saunders CL, Harte E, Griffin SJ, Maclure C, Mant J, et al. Delivery and impact of the NHS health check in the first 8 years: a systematic review. Br J Gen Pract. 2018;68(672):e449-e59. https://doi.org/10.3399/bjgp1 $8 \times 697649$

99. Teo $\mathrm{CH}, \mathrm{Ng} \mathrm{CJ}$, Booth A, White A. Barriers and facilitators to health screening in men: a systematic review. Soc Sci Med. 2016;165:168-76. https://doi.org/10.1016/j.socscimed.2016.07.023.

100. Farmer M. The Farmer review of the UK construction labour model. Construction Leadership Council; 2016.

101. Tyers C, Hicks B, Baxter K, Gilbert M. Learning from the occupational health provision on the Olympic build. Policy Pract Health Safety. 2012;10(2):10323. https://doi.org/10.1080/14774003.2012.11667779.

102. Evans M, editor Heathrow Terminal 5: health and safety leadership. Proceedings of the Institution of Civil Engineers-Civil Engineering; 2008: Thomas Telford Ltd.

103. Pinder J, Gibb A, Dainty A, Jones W, Fray M, Hartley R, et al. Engagement of smaller organisations in occupational safety and health. In: Dingwall R, Frost S, editors. Health and safety in a changing world. Abingdon, Oxford: Routledge; 2017.

104. Bust P, Gibb A, Dainty A, Cheyne A, Hartley R, Glover J, et al. Health and safety knowledge in networked organisations. In: Dingwall R, Frost $S$, editors. Health and safety in a changing world. Abingdon, Oxford: Routledge; 2017

105. Fenton S, Pinilla Roncancio M, Sing M, Sadhra S, Carmichael F. Workplace wellbeing programmes and their impact on employees and their employing organisations: a scoping review of the evidence base. Collab between Health Exchange Univ Birmingham. 2014;11(27):2014.

106. Lingard $H$, Turner M. Improving the health of male, blue collar construction workers: a social ecological perspective. Constr Manag Econ. 2015:33(1):1834. https://doi.org/10.1080/01446193.2014.997259.

107. Lingard $H$, Turner M. Promoting construction workers' health: a multi-level system perspective. Constr Manag Econ. 2017;35(5):239-53. https://doi.org/1 0.1080/01446193.2016.1274828.

108. HSE. Construction statistics in Great Britain, 2020: Health and Safety Executive; 2020; Available from: https://www.hse.gov.uk/Statistics/industry/ construction.pdf. [accessed 24 February 2021].

109. European Commission. COMMISSION STAFF WORKING DOCUMENT ex-post evaluation of the European Union occupatinal safety and health directives (REFIT evaluation) Brussels: European Commission; 2017; Available from: https://eur-lex.europa.eu/legal-content/EN/TXT/PDF/?uri=CELEX:52017SC001 0\&from=en. [accessed 24 February 2021].

110. Fishwick D, Sen D, Barker P, Codling A, Fox D, Naylor S. Health surveillance for occupational asthma in the UK. Occup Med. 2016;66(5):365-70. https:// doi.org/10.1093/occmed/kqw028.

111. Tyers C, Sinclair A, Lucy D, Cowling M, Gordon-Dseagu V, Rick J. Constructing better health final evaluation report. Health and Safety Executive: Norwich; 2007

112. Colosio C, Mandic-Rajcevic S, Godderis L, van der Laan G, Hulshof C, van Dijk F. Workers' health surveillance: implementation of the directive 89/391/ EEC in Europe. Occup Med. 2017;67(7):574-8. https://doi.org/10.1093/ occmed/kqx113.

\section{Publisher's Note}

Springer Nature remains neutral with regard to jurisdictional claims in published maps and institutional affiliations.
Ready to submit your research? Choose BMC and benefit from:

- fast, convenient online submission

- thorough peer review by experienced researchers in your field

- rapid publication on acceptance

- support for research data, including large and complex data types

- gold Open Access which fosters wider collaboration and increased citations

- maximum visibility for your research: over $100 \mathrm{M}$ website views per year

At BMC, research is always in progress.

Learn more biomedcentral.com/submissions 